\title{
THE CONCEPT OF MANAGEMENT ACCOUNTING AS AN INFORMATION SYSTEM IN THE MANAGEMENT OF COMMERCIAL ORGANIZATION PROFIT
}

\author{
КОНЦЕПЦИЯ БУХГАЛТЕРСКОГО УПРАВЛЕНЧЕСКОГО УЧЕТА КАК \\ ИНФОРМАЦИОННАЯ СИСТЕМА В УПРАВЛЕНИИ ПРИБЫЛЬЮ КОММЕРЧЕСКОЙ \\ ОРГАНИЗАЦИЕЙ
}

E. Kyshtymova, Candidate of Economic Sciences

Е.А. Кыштымова, кандидат экономических наук

N. Lytneva, Doctor of Economic Sciences

Н.А. Лытнева, доктор экономических наук

Orel State Agrarian University, Orel City, Russia

Орловский государственный аграрный университет, г. Орёл, Россия

Phone: +7 (910) 306-79-89, E-mail: ukap-lytneva@yandex.ru

Received March 2, 2012

\begin{abstract}
In the conditions of reforming of the mechanism of management there is a problem of the qualitative, reliable information necessary for regulation of economic processes with a view of maximizing profit of the commercial organizations. One of the concept directions improvement of accounting system is development of management accounting which is directed on ensuring control of profitability of the current activity of the organization first of all regarding decrease in expenses, an assessment of efficiency of managing as a whole and in a cut of divisions of the organization, the analysis of profitability of separate sectors of activity and market segments.
\end{abstract}

\section{АННОТАЦИЯ}

В условиях реформирования механизма управления встает проблема качественной, достоверной информачии, необходимой для регулирования хозяйственных процессов в целях максимизации прибыли коммерческих организаций. Одним из направлений концепџии совершенствование бухгалтерской системы является развитие управленческого учета, который направлен на обеспечение контроля экономичности текущей деятельности организации прежде всего в части снижения затрат, оценки эффективности хозяйствования в целом и в разрезе подразделений организации, анализ рентабельности отдельных секторов деятельности и сегментов рынка..

\section{KEY WORDS}

Information system; Accounting; Profit; Commercial organization; Management.

КЛЮЧЕВЫЕ СЛОВА

Информационная система; Бухгалтерский учет; Прибыль; Коммерческая организация; Управление.

Управление коммерческой организацией представляет собой процесс координации и регулирования его деятельности для достижения поставленной цели - получение максимальной прибыли. Усложнение хозяйственных связей и механизм рыночных отношений, появление новых инструментов рынка, мето-

дов и средств управления производственно хозяйственной деятельности вызвали необходимость дополнительной информации, обеспечивающей успешное функционирование организации в этих условиях. Существенные изменения произошли в технике, технологии и организации производства. Появилось 
больше разновидностей продукции, способов ее изготовления, вариантов их сочетания. Затраты и во многом результаты деятельности в настоящее время определяются не столько индивидуальными усилиями, умением человека, а уровнем технического совершенства, экономичностью работы, производительностью используемых машин и оборудования. Количество вариантов решения возникающих проблем выросло, возросла и цена неправильного управленческого решения. Появилась необходимость в переориентации основной цели бухгалтерского учета на удовлетворение внутренних потребностей фирмы, направленных на обеспечение дохода и рентабельности деятельности организации.

Бухгалтерский учет разделился на финансовый и управленческий, причем в финансовом учете постепенно обособляется и управленческая функция.

По мнению В.Б. Ивашкевича, необходимость обособления данных управленческого учета в самостоятельную систему во многом связана с усилением требований к сохранению коммерческой тайны деятельности организации, обстоятельств, при которых принимаются те или иные решения [2]. Показатели финансовой отчетности доступны если не для всех, то для многих. Это можно отнести и к финансовому учету, открытому для проверок налоговых органов, ревизоров общества или товарищества, аудиторов и т.п. Система формирования финансовой отчетности должна быть прозрачной, доступной для понимания компетентным пользователем. Учет для управления, его данные - коммерческая тайна не только для внешних пользователей, но и для управленческого персонала самой организации, не имеющего прямого отношения к решению данной проблемы.

Управленческий учет является составной частью системы управления коммерческой организации. Он призван обеспечить формирование информации для:

- контроля экономичности текущей деятельности организации в целом и в разрезе ее отдельных подразделений, видов деятельности, секторов рынка;

- планирования будущей стратегии и тактики осуществления коммерческой деятельности в целом и отдельных хозяйственных операций, оптимизации использования мате- риальных, трудовых и финансовых ресурсов организации;

- измерения и оценки эффективности хозяйствования в целом и в разрезе подразделений организации, выявления степени рентабельности отдельных видов продукции, работ, услуг, секторов и сегментов рынка;

- корректировки управляющих воздействий на ход производства и реализации продукции, товаров и услуг, уменьшения субъективности в процессе принятия решений на всех уровнях управления.

Исходя из этого, главными принципами управленческого учета являются ориентация на достижение поставленной цели предпринимательства, необходимость обеспечения альтернативных вариантов решения поставленной задачи, участие в выборе оптимального варианта и в расчетах нормативных параметров его исполнения, ориентация на выявление отклонений от заданных параметров исполнения, интерпретация выявленных отклонений и анализ.

В настоящее время на содержание управленческого учета оказывает влияние налоговый учет, который выделен в самостоятельное направление бухгалтерской деятельности. Статьей 313 гл.25 НК РФ цель налогового учета определена как «формирование полной и достоверной информации о порядке учета для целей налогообложения хозяйственных операций». Каждый факт хозяйственной деятельности классифицируется и отражается им по-своему, в соответствии с требованиями данного вида учета. Тем не менее, управленческий учет пересекается с финансовым и налоговым в части учета затрат, которые являются одним из основных факторов, влияющих на показатель прибыли. Кроме того, первичная база всех трех видов учета (финансового, управленческого и налогового) одинакова, что определяет один из аспектов их взаимосвязи.

Масловой И.А. взаимодействие финансового, управленческого и налогового учета представлено как совокупность элементов учетно-аналитической системы (УАС). Учетно-аналитическая система исследована с точки зрения тектологии, в теории коньюгации (соединение комплексов), ингрессии (вхождение элемента одного комплекса в другой) и дезингрессии (распад комплекса). Центральной составляющей в учетно-аналитической 
системе является учетная система, которая представлена в виде модели учетной системы хозяйствующего субъекта и основанная на взаимосвязи финансового, управленческого и налогового учета.

В развитие научных направлений, нами уточнена и расширена модель взаимосвязи управленческого, финансового и налогового учета применительно к исследованию затрат на производство продукции промышленных предприятий. Модель взаимосвязи учета представлена на рис. 1.

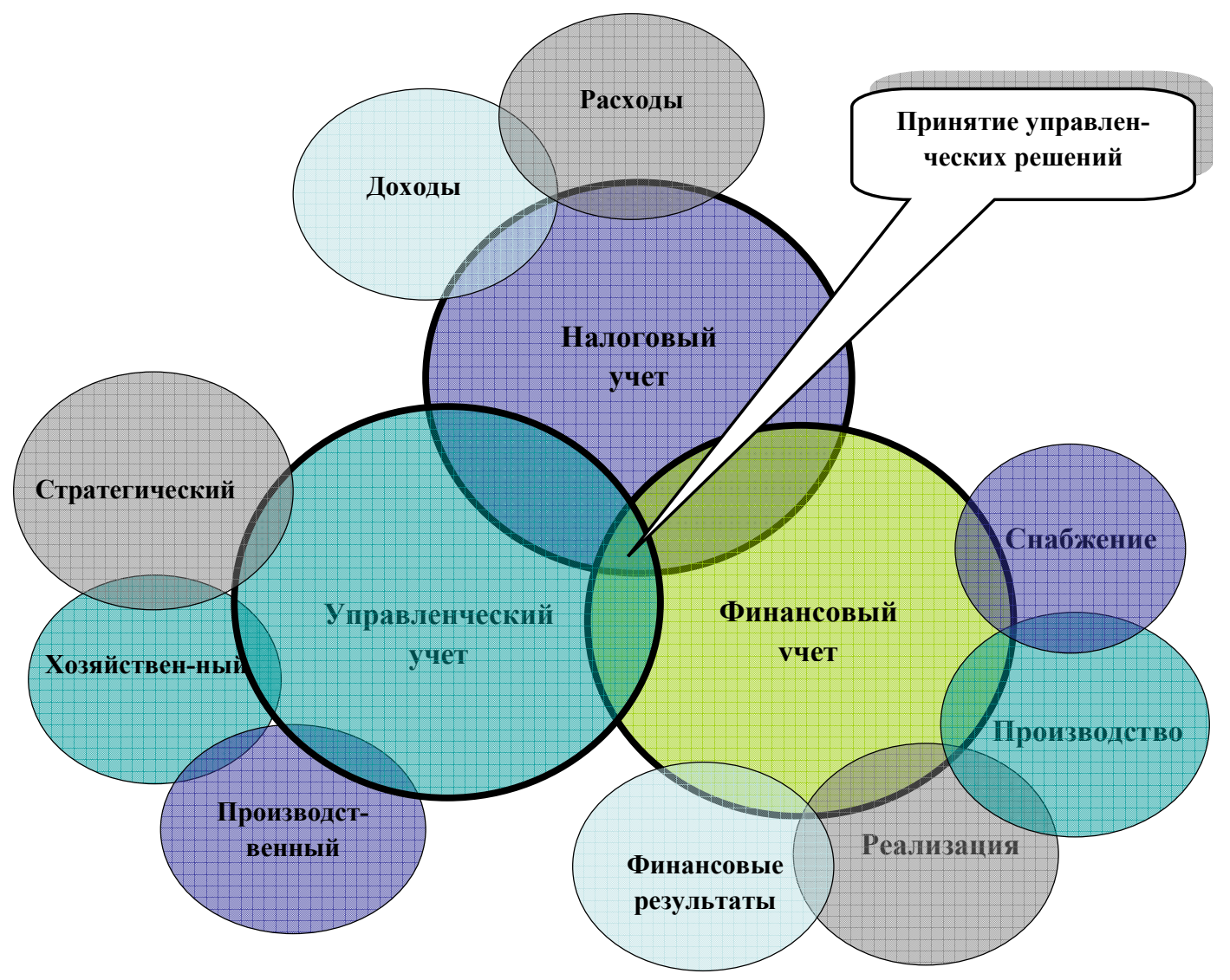

Рисунок 1 - Модель взаимосвязи управленческого, финансового и налогового учета

Результатом взаимодействия всех видов учета в рамках модели является принятие управленческих решений по составу производственных затрат, формирования себестоимости продукции и определению финансового результата по всем сегментам хозяйственной деятельности предприятий и различным уровням управления.

Несмотря на взаимосвязь управленческого, финансового и налогового учета, с нашей точки зрения, различие между ними, в первую очередь, состоит в уровне детализации расходов и затрат. Анализ содержания национальных стандартов учета позволил нам определить, что перед каждым учетом стоят разные цели и задачи, используются определенные способы учета объектов, формируются неод- нородные конечные информационные результаты. При этом стратегической целью является эффективное функционирование предприятия.

Отличительные особенности управленческого, финансового и налогового учета обобщены в табл. 1.

При организации финансового, налогового и управленческого учета предприятие должно руководствоваться специально разработанной учетной политикой, основанной на их взаимосвязи при определении способов и методов учета производственных затрат, плана счетов, бухгалтерских, налоговых и аналитических регистров [1].

В настоящее время основы формирования (выбора и обоснования) и раскрытия 
(придания гласности) учетной политики организаций, являющихся юридическими лицами по законодательству Российской Федерации (кроме кредитных организаций и бюджетных учреждений), устанавливаются ПБУ 1/98. Пунктом 2 ПБУ 1/98 определено, под учетной политикой организации понимается принятая совокупность способов ведения бухгалтерского учета - первичного наблюдения, стоимостного измерения, текущей группиров- ки и итогового обобщения фактов хозяйственной деятельности. К способам ведения бухгалтерского учета относятся способы группировки и оценки фактов хозяйственной деятельности, погашения стоимости активов, организации документооборота, инвентаризации, способы применения счетов учета, системы регистров бухгалтерского учета, обработки информации и иные соответствующие способы и приемы.

Таблица 1 - Отличительные особенности управленческого, финансового и налогового учета

\begin{tabular}{|c|c|c|c|}
\hline $\begin{array}{l}\text { Сравнительная ха- } \\
\text { рактеристика }\end{array}$ & Управленческий учет & Финансовый учет & Налоговый учет \\
\hline $\begin{array}{c}\text { Юридический аспект } \\
\text { организации }\end{array}$ & $\begin{array}{c}\text { Организация учета необя- } \\
\text { зательно }\end{array}$ & $\begin{array}{c}\text { Организация учета обя- } \\
\text { зательно }\end{array}$ & $\begin{array}{c}\text { Организация учета обяза- } \\
\text { тельно }\end{array}$ \\
\hline Цель учета & $\begin{array}{c}\text { Принципы учета форми- } \\
\text { руются организацией са- } \\
\text { мостоятельно }\end{array}$ & $\begin{array}{c}\text { Принципы учета осно- } \\
\text { ваны на общепринятых } \\
\text { принципах бухгалтер- } \\
\text { ского учета }\end{array}$ & $\begin{array}{c}\text { Принципы учета основа- } \\
\text { ны на положениях нало- } \\
\text { гового законодательства }\end{array}$ \\
\hline $\begin{array}{c}\text { Внутренний доку- } \\
\text { мент, опреде ляю- } \\
\text { щий порядок веде- } \\
\text { ния учета }\end{array}$ & $\begin{array}{c}\text { Учетная политика для } \\
\text { целей ведения управлен- } \\
\text { ческого учета }\end{array}$ & $\begin{array}{c}\text { Учетная политика для } \\
\text { целей ведения финан- } \\
\text { сового учета }\end{array}$ & $\begin{array}{c}\text { Учетная политика для } \\
\text { целей ведения налогового } \\
\text { учета }\end{array}$ \\
\hline Степень точности & $\begin{array}{l}\text { Показатели могут иметь } \\
\text { приближен ный характер }\end{array}$ & $\begin{array}{l}\text { Высокая степень точ- } \\
\text { ности }\end{array}$ & $\begin{array}{c}\text { Высокая степень точно- } \\
\text { сти }\end{array}$ \\
\hline $\begin{array}{c}\text { Пользователи ин- } \\
\text { формации }\end{array}$ & $\begin{array}{c}\text { Различные уровни внут- } \\
\text { рифирменного управления }\end{array}$ & $\begin{array}{c}\text { Внешние и внутренние } \\
\text { пользователи бухгал- } \\
\text { терской информации }\end{array}$ & $\begin{array}{c}\text { Внешние и внутренние } \\
\text { пользователи налоговой } \\
\text { информации }\end{array}$ \\
\hline Масштабы учета & $\begin{array}{l}\text { От небольших производ- } \\
\text { ственных участков до ор- } \\
\text { ганизации в целом }\end{array}$ & $\begin{array}{c}\text { Вся организация в це- } \\
\text { лом }\end{array}$ & $\begin{array}{c}\text { От отдельных объектов } \\
\text { до налогообложения } \\
\text { прибыли }\end{array}$ \\
\hline Период учета & Прошлое и будущее & $\begin{array}{l}\text { Итоги прошлого пе- } \\
\text { риода }\end{array}$ & $\begin{array}{l}\text { Налогообложение опера- } \\
\text { ций прошлого периода }\end{array}$ \\
\hline $\begin{array}{c}\text { Объект учета и от- } \\
\text { четности }\end{array}$ & $\begin{array}{c}\text { Структурные подразделе- } \\
\text { ния организации }\end{array}$ & $\begin{array}{c}\text { Организация как юри- } \\
\text { дическое лицо с учетом } \\
\text { дочерних компаний и } \\
\text { подразделений }\end{array}$ & $\begin{array}{c}\text { Организация как юриди- } \\
\text { ческое лицо с учетом } \\
\text { дочерних компаний и } \\
\text { подразделений }\end{array}$ \\
\hline Оперативность & $\begin{array}{c}\text { Любая: ежедневно, еже- } \\
\text { недельно и т.д. }\end{array}$ & $\begin{array}{l}\text { Ежемесячно, ежеквар- } \\
\text { тально, по полугодиям }\end{array}$ & По налоговым периодам \\
\hline $\begin{array}{c}\text { Принцип группиров- } \\
\text { ки расходов }\end{array}$ & $\begin{array}{l}\text { По статьям калькуляции } \\
\text { себестоимости продукции }\end{array}$ & $\begin{array}{l}\text { По экономическим } \\
\text { элементам }\end{array}$ & $\begin{array}{l}\text { По экономическим эле- } \\
\text { ментам }\end{array}$ \\
\hline $\begin{array}{c}\text { Использование ме-- } \\
\text { тода двойной записи } \\
\text { и регистров учета }\end{array}$ & $\begin{array}{l}\text { Использование не обяза- } \\
\text { тельно, регистры управ- } \\
\text { ленческого учета }\end{array}$ & $\begin{array}{l}\text { Использование обяза- } \\
\text { тельно, регистры бух- } \\
\text { галтерского учета }\end{array}$ & $\begin{array}{c}\text { Использование не преду- } \\
\text { смотрено, налоговые ре- } \\
\text { гистры }\end{array}$ \\
\hline $\begin{array}{l}\text { Валюта, в которой } \\
\text { ведется учет }\end{array}$ & Любая валюта & Рубли & Рубли \\
\hline $\begin{array}{c}\text { Формы предоставле- } \\
\text { ния отчетной ин- } \\
\text { формации }\end{array}$ & $\begin{array}{c}\text { Разрабатывается и утвер- } \\
\text { ждается предприятием }\end{array}$ & $\begin{array}{c}\text { Регулируется стандар- } \\
\text { тами по бухгалтерско- } \\
\text { му учету }\end{array}$ & $\begin{array}{c}\text { Регулируется налоговы- } \\
\text { ми органами }\end{array}$ \\
\hline $\begin{array}{c}\text { Периодичность } \\
\text { представления от- } \\
\text { четности }\end{array}$ & $\begin{array}{c}\text { По мере необходи мости, } \\
\text { в соответст вии с принци- } \\
\text { пами внутреннего управ- } \\
\text { ления }\end{array}$ & $\begin{array}{c}\text { Квартал, полугодие, } 9 \\
\text { месяцев, год }\end{array}$ & $\begin{array}{c}\text { По мере окончания нало- } \\
\text { гового периода }\end{array}$ \\
\hline
\end{tabular}


По мнению С.А. Рассказовой-Николаевой в настоящее время предполагается сближение учетных систем путем:

- выбора главной учетной системы, на базе которой будут строиться другие учетные системы;

- выбора в качестве основы для построения главной учетной системы правил и способов, предусмотренных международными стандартами отчетности и пересмотра, в этой связи, национальных стандартов бухгалтерского учета и отчетности;

- приближения правил налогового и бухгалтерского учета [3].

Система учета затрат в организации является основным участком работы бухгалтерии и, можно сказать, всей системы управления организацией, так как здесь собирается информация о фактических издержках, а значит, создаются основы для подсчета фактической прибыли, т.е. расчета того показателя, ради достижения которого и была создана организация. Поэтому при разработке учетной политики особое значение с нашей точки зрения, имеет определение всей совокупности вопросов финансового, управленческого и налогового учета затрат и способов калькулирования себестоимости продукции.

На наш взгляд, совокупность решаемых с помощью учетной политики вопросов можно разделить на методические и организационнотехнические (рис. 2).

Методический аспект учетной политики затрат на производство влияет на порядок калькулирования себестоимости готовой продукции, в частности, определение производственной и полной себестоимости, формирования финансовых результатов деятельности организации, на оценку ее финансового состояния.

Организационно-технический аспект учетной политики организации включает приемы и методы организации технологического процесса работы бухгалтерскофинансовой службы предприятия, направленные на успешное выполнение задач, стоящих перед информационной системой, обеспечивающей процесс принятия управленческих решений.

Действующими в настоящее время нормативными документами предусмотрены два варианта учета затрат на производство: калькуляционный и применение системы «Директ-костинг» .
Калькуляционный способ затрат предусматривает отражение затрат отчетного периода по дебету счетов учета затрат на производство (20 «Основное производство», 23 «Вспомогательные производства», 25 «Общепроизводственные расходы», 26 «Общехозяйственные расходы» и др.) с кредита счетов учета ресурсов. Затраты отражаются с подразделением на прямые и косвенные (накладные), относимые в дебет собирательнораспределительных счетов 25 и 26. Расходы, собранные на счетах 25 и 26, подлежат списанию в конце отчетного периода в дебет счетов 20 или 23 по принадлежности с одновременным их распределением между объектами калькулирования, в разрезе которых организуется аналитический учет, пропорционально той или иной базе.

Второй вариант предполагает разделение всех затрат за отчетный период на производственные, обусловленные ходом производственного процесса, и периодические, более связанные с длительностью отчетного периода. Он предусматривает применение на практике основной идеи западной системы «Директ-костинг» (Direkt-Costing-System, англ., амер. - система учета «Директ-костинг», Deckungsbeitragsrech-nung или Grenzkostenrechnungssystem, нем. - система учета сумм покрытия, или система учета граничных (предельных) затрат). Вариант предусматривает разделение общих текущих затрат отчетного периода по признаку их взаимосвязи с производством на производственные (прямые, условно-переменные) и периодические (косвенные, условно-постоянные) и калькулирование неполной, ограниченной себестоимости по объектам калькулирования.

На Западе эта себестоимость может включать в себя только прямые или переменные затраты (т.е. зависящие от изменения объемов производства), она может калькулироваться только на основе производственных расходов (т.е. расходов, связанных с изготовлением данной продукции, выполнением работ или оказанием услуг, даже если они носят косвенный характер). Несмотря на различную полноту включения в себестоимость объекта калькулирования разных видов расходов, общим для этого подхода является то, что другие виды затрат, которые также по своей экономической сущности составляют часть текущих издержек, не включаются в калькуляцию, а возмещаются общей суммой из выручки или валовой прибыли. В этом состоит ос- 
новная отличительная особенность системы учета неполной себестоимости.

Рассказова-Николаева С.А. определяет два основных преимущества второго подхода к учету затрат и результатов, которые заключаются в следующем: с одной стороны, происходит снижение трудоемкости учета, его упрощение, с другой стороны, в связи с иным подходом к калькулированию появляются дополнительные аналитические и управленче- ские возможности [3]. Первое преимущество реально может быть реализовано при организации учета на малых предприятиях.

Другое преимущество - создание самостоятельной системы внутреннего управленческого учета, необходимой в условиях рынка на предприятиях средних и крупных, со сложной внутренней структурой, с крупносерийным или массовым типом производства.

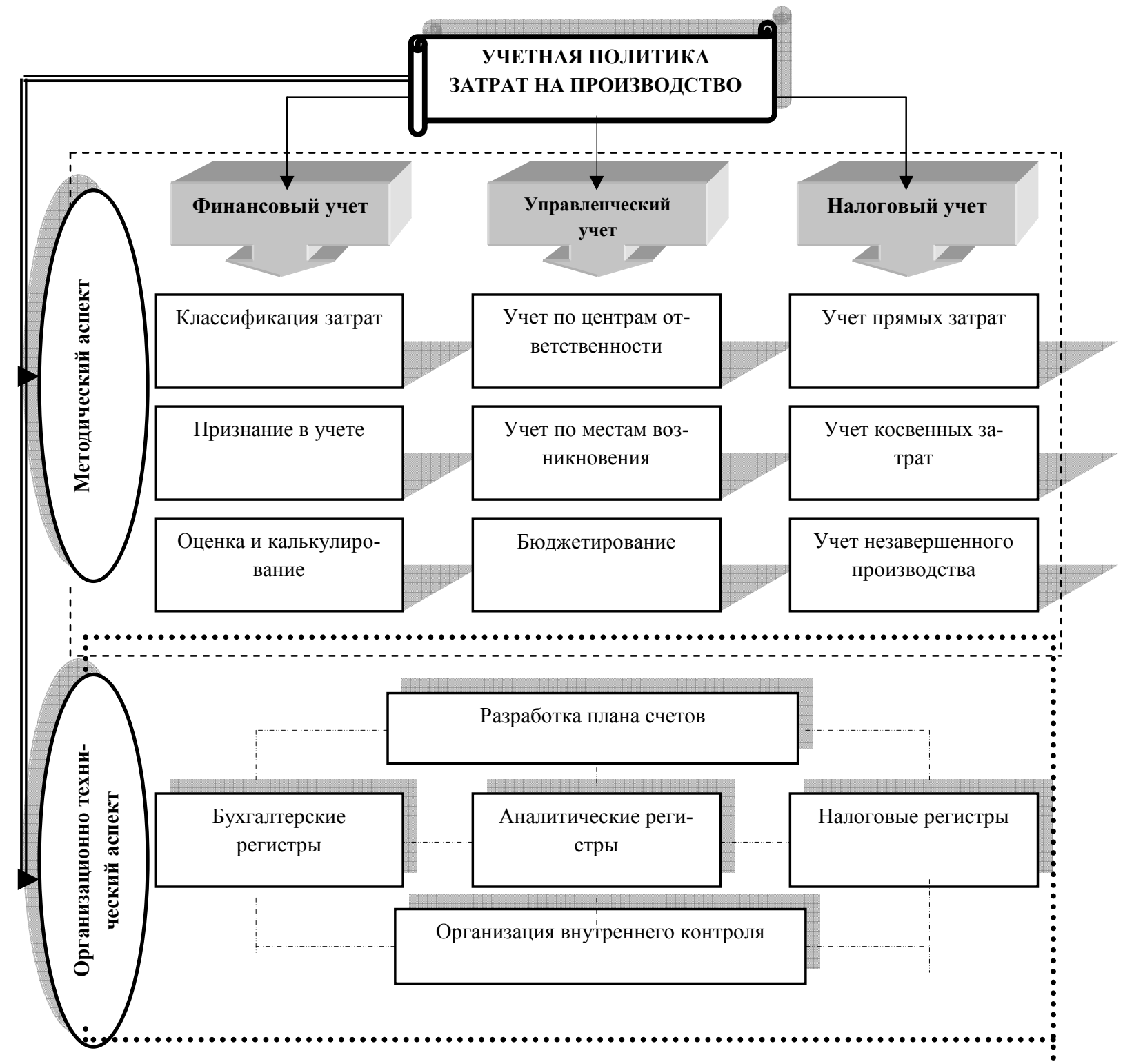

Рисунок 2 - Содержание учетной политики затрат на производство и калькулирование себестоимости продукции

Подводя итог сказанному, можно предложить два варианта учета затрат на производство и расчета финансового результата, один из которых организация должна выбрать, закрепив его в Приказе об учетной политике.
1. Организация калькулирует полную производственную себестоимость реализованной продукции (работ, услуг).

2. Организация признает управленческие расходы в себестоимости проданных продук- 
ции, товаров, работ, услуг полностью в отчетном году их признания в качестве расходов по обычным видам деятельности.

Методика управленческого учета затрат на производство и калькулирование себестоимости продукции определяется учетной политикой предприятия исходя из особенностей деятельности, структуры, организации управления производственным процессом.

По мнению Авровой И.А. и Андреева А.В. под калькулированием себестоимости понимается исчисление себестоимости произведенной продукции, выполненных работ и оказанных услуг. В планировании, учете и анализе себестоимости отдельных видов продукции определяющими являются плановая, нормативная, фактическая и хозрасчетная себестоимость.

Процесс калькулирования себестоимости включает в себя следующие виды работ по исчислению себестоимости:

- продукции работ и услуг вспомогательных производств, использованных основным производством;

- промежуточных продуктов (полуфабрикатов) подразделений основного производства, используемых на последующих стадиях производства;

- продукции подразделений предприятия для выявления результатов их деятельности;

- всего товарного выпуска предприятия;

- выпуска по видам продукции и полуфабрикатов собственного производства, реализуемых на сторону;

- единицы вида готовой продукции, выполненных работ и оказанных услуг.

Методы калькулирования себестоимости продукции определяется организацией самостоятельно и утверждается учетной политикой.

Исходя из определенных факторов, перспектива управленческого учета, по нашему мнению, имеет следующие направления:

- стратегический управленческий учет;

- управленческий анализ.

Сравнительно новым и перспективным является выделение в системе управленческого учета стратегического управленческого учета для высшего руководства и оперативного управленческого учета для внутреннего менеджмента.

Термин "стратегический управленческий учет" появился в США и странах Западной Европы в восьмидесятых годах двадцатого века, однако очень широкого применения в то время он не нашел.

Серьезные дискуссии касательно стратегического управленческого учета стали появляться уже в девяностые годы.

В России стратегический управленческий учет практически отсутствует. Однако его отдельные методы и подходы уже начинают использоваться.

Стратегический управленческий учет нацелен на перспективу и рассматривается как потенциальное направление развития, которое повысит значение управленческого учета .

С другой стороны, стратегический управленческий учет представляет учетноаналитическую систему, которая призвана обеспечить информационные потребности стратегического менеджмента.

Принципиальной особенностью управленческого учета является необходимость определения затрат не только по предприятию в целом, но и по центрам ответственности и местам формирования внутри организации [4].

Как показывает практика, учет затрат по местам их возникновения и цен $\urcorner$ трам ответственности ведется практически на каждом предприятии. Однако в организации такого учета отсутствует научно-обоснованная методика, что снижает контрольные функции и аналитичность информации, сформированной в управленческом учете, необходимой для принятия экономически обоснованных решений по управлению затратами производства и калькулированию себестоимости продукции.

Организация учета по местам возникновения затрат и центрам ответственности позволяет децентрализовать управление затратами, наблюдать за их формированием на всех уровнях управления, использовать специфические методы контроля расходов с учетом особенностей деятельности каждого подразделения, выявлять виновников непроизводительных затрат и, в конечном итоге, существенно повысить экономическую эффективность хозяйствования.

Дифференциацию мест возникновения и центров затрат целесообразно рассматривать на макро и микро уровнях иерархического управления. С этой целью нами разработана модель управления затратами по местам возникновения и центрам затрат, которая позволяет определить порядок формирования управленческой информации на уровне отрас- 
ли, народного хозяйства в целом, холдинга, компании, предприятия.

Управление затратами на макро уровне предполагает их исследование по центрам управления: основное и вспомогательное производство, обслуживающие хозяйства, сферу управления предприятия и непроизводственную сферу. На каждом месте возникновения затрат, вне зависимости от сегмента и центра управления информация формируется по общепринятым элементам затрат, что обусловливается взаимосвязью управленческого и финансового учета.

Управление затратами на микро уровне предусматривает классификацию мест возникновения затрат производства в рамках отдельного предприятия. Распределение и контроль затрат осуществляется по центрам управления и центрам затрат. Критерии обособления центров затрат зависят от специфики предприятия. C нашей точки зрения, центры затрат можно сгруппировать в следующие виды: общепроизводственные, внутрипроизводственные и технологические.

Общепроизводственные центры затрат производства основаны на принципе структуризации предприятия, то есть определение в качестве центров ответственности производств, цехов, участков, служб, отделов, бригад.

Внутрипроизводственные центры затрат объединены их техническим характером. В качестве центров затрат выступают группы оборудования, машины и агрегаты, производственные технологические линии, рабочие места.

В однородных производствах в качестве центров затрат могут выступать отдельные этапы производственного процесса: стадии и фазы производства, передел, производство отдельных конструкций, деталей и полуфабрикатов [5].

Разработанная нами модель управления затратами по местам возникновения и центрам затрат предназначена для определения структуры методики управленческого учета. Формирование содержания методики управленческого учета затрат будет осуществляться с учетом специфики предприятия, вида деятельности и вида выпускаемой продукции.

Основываясь на взаимосвязи финансового и управленческого учета при использовании метода двойной записи предприятия разрабатывают специальный план счетов центров затрат с учетом специфики и видов деятельности. Он может быть увязан с действующим планом счетов бухгалтерского учета, а может ориентироваться на применение специальных счетов управленческой бухгалтерии.

Одним из вариантов системных записей в управленческом учете является ведение счетов отклонений от нормативной величины расходов. В этом случае обороты по дебету и кредиту счетов сырья и материалов, затрат на производство, готовой продукции отражают по нормативной стоимости. Все расхождения между нормативными и фактическими издержками снабжения, производства, сбыта относят в дебет или кредит соответствующих счетов отклонений. Таким образом, по местам и центрам формирования учитывают лишь отклонения от норм и нормативов.

Степень применения управленческого учета центрам ответственности для каждого предприятия индивидуальна. Оптимальный вариант применения управленческого учета в том или ином сегменте может быть найден только после детального анализа конкретных условий деятельности и потребностей предприятия. Возможны два варианта распределения затрат по центрам ответственности предприятия:

- все прямые и косвенные затраты распределяются по центрам ответственности независимо от того, к какой продукции они относятся;

- по центрам ответственности распределяются только косвенные затраты, которые нельзя отнести по прямому признаку на конкретные виды продукции. Прямые затраты включаются непосредственно в себестоимость продукции, в состав затрат определенных центров они не входят.

Каждый из представленных вариантов имеет свои достоинства и недостатки и должен применяться после анализа методологических и организационных особенностей применения управленческого учета на конкретном сегменте деятельности предприятия.

Детализация коммерческих и административных расходов по центрам ответственности предприятия создает условия для повышения точности определения себестоимости производимой продукции. 


\section{БИБЛИОГРАФИЯ}

Вахрушина М.А. Бухгалтерский управленческий учет: Учебник для вузов. - М. :Омега-Л, 2006. - 576 с.

Ивашкевич В.Б. Бухгалтерский управленческий учет: учеб. для вузов. - М.: Экономисть, 2006. $-618 \mathrm{c}$.

Кузнецов Б.Т. Стратегический менеджмент. М: Юнити-Дана, 2007.-623 с.

Томпсон А.А. мл., Стрикланд А. Дж. III. Стратегический менеджмент. Концепции и ситуации. - 9-е изд. - М.: ИНФРА-М, 2000 .
Филобокова Л.Ю. SNW-, STEP- и SWOTанализв системе стратегического управления малым предпринимательством / Экономический анализ: теория и практика. - №17. - 2007. - с. 23-30. 